\title{
บUsisersily
}

\section{Characterization of flammability and fire resistance of carbon fibre reinforced thermoset and thermoplastic composite materials}

Zhang, J., Delichatsios, M., Fateh, T., Suzanne, M., \& Ukleja, S. (2017). Characterization of flammability and fire resistance of carbon fibre reinforced thermoset and thermoplastic composite materials. Journal of Loss Prevention in the Process Industries, 50(Part A), 275-282. https://doi.org/10.1016/j.jlp.2017.10.004

Link to publication record in Ulster University Research Portal

Published in:

Journal of Loss Prevention in the Process Industries

Publication Status:

Published (in print/issue): 30/11/2017

DOI:

10.1016/j.jlp.2017.10.004

Document Version

Author Accepted version

\section{General rights}

Copyright for the publications made accessible via Ulster University's Research Portal is retained by the author(s) and / or other copyright owners and it is a condition of accessing these publications that users recognise and abide by the legal requirements associated with these rights.

\section{Take down policy}

The Research Portal is Ulster University's institutional repository that provides access to Ulster's research outputs. Every effort has been made to ensure that content in the Research Portal does not infringe any person's rights, or applicable UK laws. If you discover content in the Research Portal that you believe breaches copyright or violates any law, please contact pure-support@ulster.ac.uk. 


\section{Accepted Manuscript}

Characterization of flammability and fire resistance of carbon fibre reinforced thermoset and thermoplastic composite materials

Jianping Zhang, Michael A. Delichatsios, Talal Fateh, Mathieu Suzanne, Sebastian Ukleja

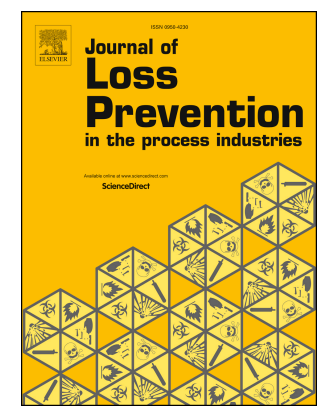

PII:

S0950-4230(17)30880-X

DOI: 10.1016/j.jp.2017.10.004

Reference: JLPP 3603

To appear in: Journal of Loss Prevention in the Process Industries

Received Date: 20 March 2017

Revised Date: 4 August 2017

Accepted Date: 9 October 2017

Please cite this article as: Zhang, J., Delichatsios, M.A., Fateh, T., Suzanne, M., Ukleja, S., Characterization of flammability and fire resistance of carbon fibre reinforced thermoset and thermoplastic composite materials, Journal of Loss Prevention in the Process Industries (2017), doi: 10.1016/j.jp.2017.10.004.

This is a PDF file of an unedited manuscript that has been accepted for publication. As a service to our customers we are providing this early version of the manuscript. The manuscript will undergo copyediting, typesetting, and review of the resulting proof before it is published in its final form. Please note that during the production process errors may be discovered which could affect the content, and all legal disclaimers that apply to the journal pertain. 


\section{Characterization of Flammability and Fire Resistance of Carbon}

Fibre Reinforced Thermoset and Thermoplastic Composite

\section{Materials}

Jianping Zhang *, Michael A Delichatsios, Talal Fateh, Mathieu Suzanne and Sebastian Ukleja

Institute for Fire Safety Engineering Research and Technology (FireSERT), School of the Built Environment and Built Environment Research Institute, Ulster University, Newtownabbey, BT37 0QB, United Kingdom

* Corresponding author:

Jianping Zhang

Tel.: +44 (0)2890366460

Email: j.zhang@uslter.ac.uk

Postal address: FireSERT, School of the Built Environment, Ulster University, Newtownabbey, BT37 0QB, UK 


\section{Abstract}

This paper presents a complete methodology for the assessment and modelling of the flammability and fire resistance of carbon fibre (CF) reinforced thermosets (three different types of epoxy) and a thermoplastic resin (PEEK) used for the fuselage of modern aircrafts. A global ranking of the composites is presented for thermally thin conditions (1 $\mathrm{mm}$ thick) using thermogravimetric analysis (TGA) and cone calorimeter measurements and four parameters for thermally intermediate conditions ( $4 \mathrm{~mm}$ thick) including a fire growth parameter, a smoke parameter, a toxicity parameter and the final mass residue. In addition, the shielding/charring effect of CF layers was characterised by modelling the reduction in the imposed heat flux due to this layer together with the previously determined thermal properties. By measuring the temperature at the back insulated surface of the composite in the cone calorimeter, we can also assess the fire resistance (integrity) of the composite and the heat transferred to the insulation behind this fuselage composite material in the aircraft application.

Keywords: Carbon fibre reinforced polymer composite, epoxy, PEEK, cone calorimeter, thermogravimetric analysis, pyrolysis model

\section{Introduction}

In recent years, fibre-reinforced polymer (FRP) composites have been increasingly used, as alternatives to metals, in high performance applications, which require light weight as well as outstanding mechanical, thermal and chemical properties. The FRP composites are usually made of glass, carbon or extended-chain polyethylene fibres with a polyester, vinyl ester, epoxy or phenolic resin matrix. In the aviation industry, carbon fibres (CFs) are generally preferred to glass fibres because of their high specific tensile modulus and lower weight.

The thermal decomposition and flammability of carbon fibre reinforced polymer (CFRP) 
composites has attracted significant research attention (e.g., Noel, et al., 1998, Régnier and Fontaine, 2001; Toldy et al., 2011; Patel et al., 2011; Branca, et al., 2011; Dao et al., 2013; Rallini et al., 2013; Jubsilp, et al., 2013). Noël et al. (1998) and Régnier and Fontaine (2001) focused on thermal degradation of carbon-fibre reinforced epoxy using thermogravimetric analysis (TGA) and differential scanning calorimetry (DSC). Toldy et al. (2011) examined the fire retardancy using limiting oxygen index (LOI), UL94 and cone caloirmeter and found that the intumescence-hindering effect of the fibre reinforcement was overcome by forming a multilayer composite, consisting of reference composite core and intumescent epoxy resin coating layer. Patel et al. (2011)] investigated the thermal decomposition and flammability of PEEK (polyether ether ketone) and its carbon and glass-fibre composites. Branca et al. (2011) studied the oxidation behaviour of a toughened epoxy resin reinforced with carbon fibres based on thermogravimetric analysis (TGA) measurements. Dao et al. (2013) studied the influence of carbon fibre concentration on the fire reaction properties and on the gaseous species release of an epoxy resin. Rallini et al. (2013) investigated the effect of boron carbide nanoparticles on the fire reaction and fire resistance of carbon fibre/epoxy composites. Jubsilp et al. (2013) examined the flammability and thermomechanical properties of Dianhydride-modified Polybenzoxazine composites reinforced with carbon fibre using TGA and FTIR (Fourier transform infrared spectroscopy). The cone calorimeter data in these studies have shown that (i) the carbon fibre increases the ignition delay time due to high conductivity of carbon fibre and decreases the heat release rate due to the thermal radiation shield of the carbon fibre char and (ii) the carbon fibre concentration has a very important effect on the fire retardancy of the fibre-reinforced composites.

Whist these studies certainly provide useful insight into the flammability and/or fire resistance of carbon fibre reinforced polymer composites, extreme caution should be taken if one wishes to extrapolate these test results to real situations because the sample size used in 
these tests (as in most laboratory studies) is much smaller than that being used in the end products,. As a result, it is highly desirable and cost effective to be able to assess or model the flammability of materials by means of small scale-tests before new formulations progress in large-scale production of products made out of these materials. The authors have developed a systematic way towards achieving this goal (Zhang et al., 2009; Zhang and Delichatsios, 2010; Zhang et al., 2010; Zhang et al., 2012; Delichatsios and Zhang, 2012) by performing experiments in microscale (TGA/FTIR/MDSC/ATR), mesoscale (tube furnace, cone calorimeter, and universal flammability apparatus - controlled oxidizer) and larger-scale such as SBI and ISO Room Corner tests. Specifically, we have used the microscale tests to extract flammability and toxicity material properties, which through material pyrolysis analyses and computational fluid dynamics (CFD) gaseous combustion modelling, have been applied to predict the fire behaviour in the cone calorimeter and then, to predict that in larger-scale tests such as SBI and ISO room configuration (Zhang et al., 2010; Zhang et al., 2012; Delichatsios and Zhang, 2012).

In parallel, the authors' group also developed (Suzanne et al., 2014), based on these measurements, a set of fundamental parameters that can characterize and compare the flammability and toxicity of materials and differentiate their fire performance even after they have achieved the passing of a standard approval test as for example the UL-94 test. The fire performance and toxicity of polymers is characterised using basically three and possibly five parameters based on measurements in the cone calorimeter at different heat fluxes supported by thermogravimetric analysis (TGA), including (i) a fire spread and growth parameter, (ii) a smoke parameter, (iii) inefficiency of combustion, (iv) mass residue and (v) heat release rate for thermally thin materials.

In this paper, both methods are applied to characterise and model the flammability and fire resistance of carbon fibre reinforced epoxy and PEEK (polyether ether ketone) resins as 
part of the European project, AircraftFire (http://www.aircraftfire.eu). Epoxy and PEEK are commonly used for the fuselage of modern aircrafts. It is well known that epoxy resins have excellent mechanical performance, chemical resistance and lower shrinkage on cure (Toldy et al., 2011), but they exhibit low fire resistance due to their chemical nature. In comparison, PEEK resins have excellent thermal, chemical and mechanical properties. The excellent thermal properties were attributed to the stability of the aromatic backbone comprising the bulk of the monomer unit (Patel et al., 2011). The aim of this paper is hence to investigate and compare the fire performance of carbon-fibre reinforced thermoset and thermoplastics and apply and validate our previously developed methodologies based on laboratory scale materials to predict the fire behaviours of these complex polymer composites that are being used in the aviation industry.

This paper is organised in the following way. Firstly, the description and derivation of the flammability and toxicity parameters are discussed briefly (more details can be found in (Suzanne et al., 2014), followed by the deduction of the effective flammability properties (thermal, ignition, and combustion) from the ignition tests. Subsequently, the pyrolysis model previously developed and validated for polymer nanocomposites and intumescent coatings (Zhang et al., 2009; Zhang and Delichatsios, 2010; Zhang et al., 2012) is used to model the degradation of the carbon fibre composites. Finally, a methodology is also proposed to assess the fire resistance (integrity) of the composite material based on the insulated back surface temperature of the composites measured in the cone calorimeter.

\section{Flammability and toxicity parameters}

\subsection{Fire Growth Parameter}

The fire growth parameter is determined based on the measurement performed in the cone 
calorimeter at an external heat flux of $50 \mathrm{~kW} / \mathrm{m}^{2}$ as:

$$
\text { Fire Growth Parameter }=\frac{P H R R^{2}}{t_{i g n}}
$$

where PHHR is the peak heat release rate $\left(\mathrm{kW} / \mathrm{m}^{2}\right)$ and $t_{\text {ign }}$ the time to ignition (s).

This parameter represents a characteristic fire spread speed for materials burning in a vertical orientation for turbulent burning conditions (Delichatsios, 2007). The higher the value of this parameter, the more prone to flame spread the material is (Delichatsios, 1995; Nazare et al., 2002). It is worth noting that the present definition of the fire growth parameter is different from the one in (Sundström, 2015; Tewarson, 2008), in which the FIGRA (fire growth rate index) is defined as the ratio of PHRR to the time to reaching PHRR, because cone calorimeter represents a fixed area fire whereas SBI a growing spreading fire.

\subsection{Smoke Parameter}

The smoke parameter is defined as the ratio of the smoke yield, $y_{s}$, and the effective heat of combustion, $\Delta H_{c}$, as measured in the cone calorimeter as:

$$
\text { Smoke parameter }=y_{s} / \Delta H_{c}
$$

We include the heat of combustion in Eq. 2 because the amount of smoke released during a fire depends not only on the smoke yield but also on the mass pyrolysis rate. For a given heat release rate, if two materials have the same smoke yield, it is the one having the lower effective heat of combustion that releases more smoke. Note that the carbon monoxide effects are included in the smoke parameter because the $\mathrm{CO}$ yield is proportional to the smoke yield, at least for over-ventilated conditions (Ukleja et al., 2013).

\subsection{Toxicity Parameter}

The toxicity parameter is defined as the ratio of the effective heat of combustion of the fire retarded polymer $\left(\Delta H_{C, F R \_p o l y m e r}\right)$ to that of the neat polymer $\left(\Delta H_{c, \text { neat_polymer }}\right)$ : 


$$
\text { Toxicity parameter }=1-\frac{\Delta H_{C, F R \_p o l y m e r}}{\Delta H_{C, \text { neat_polymer }}}
$$

This equation can be modified to take into consideration different weight percentages of the base polymer in different formulations (Suzanne et al., 2014). This parameter represents unburned high molecular hydrocarbon, which is the main source of toxic gases different from CO. The correlation of this parameter with toxic gases from the tube furnace is shown in (Ukleja et al., 2013). When this parameter is greater than zero, this signifies that more of the FR polymer (compared to the base polymer) is released as unburned components including $\mathrm{CO}$ and smoke.

\subsection{Mass Residue}

This parameter describes how much of the initial material is left behind as residue after pyrolysis/combustion. This is not significant for fire spread and growth but it can provide the amount of total fuel load in a fully developed fire. This quantity can be measured in the cone calorimeter or in TGA in nitrogen with experiments showing that these quantities so measured have close values (Delichatsios and Zhang, 2010).

\subsection{Heat Release Rate for Thermally Thin Materials}

We characterize the heat release rate under thermally thin burning conditions by the maximum pyrolysis rate in TGA multiplied by the effective heat of combustion in the cone calorimeter normalized by the initial mass and finally divided by the heating rate, which is nearly proportional to the maximum pyrolysis rate.

$$
\text { Heat release rate for thermally thin conditions }=\frac{1}{m_{\text {initial }}}\left(\frac{d m}{d t}\right)_{\text {max }} \frac{\Delta H_{c}}{\text { Heating rate }}
$$

This parameter is very similar to that proposed by Lyon and Walters (2002) with the difference being that we use the effective heat of combustion measured in the cone calorimeter whereas the total heat of combustion was used in (Lyon and Walters, 2002). 


\section{Experimental Details}

\subsection{Materials}

In total, four CFRP composites, which are used for the fuselage of modern aircrafts, were provided by Airbus France (a consortium partner in the AircraftFire project), including three different types of epoxy resins and a thermoplastic resin (PEEK). The epoxy resin contains Bisphenol F Epoxy and Tryglycidyl-P-Aminophenol and the PEEK was semi-crystalline Victrex PEEK ${ }^{\mathrm{TM}}$ grade $450 \mathrm{P}$. The epoxy resin and PEEK are around $30 \%$ by weight. The main difference of the epoxy resins is the layup of the carbon fibre layers. Unfortunately, the exact composition of the materials and the orientation of carbon fibres or other additional components of the materials were not available due to commercial confidentiality. It is essential to point out that this lack of information on the materials does not have an adverse effect on the present methodology. In fact, one of the advantages of the present methodology is that it could be applied to any material if only the required set of tests are carried out. For simplification and consistency with the project reports, the three epoxy containing materials will be referred to as AcF1, AcF2 and AcF7 and the PEEK containing material AcF6. The thickness of the samples for cone calorimeter tests is $4 \pm 0.1 \mathrm{~mm}$. When presenting the results for the flammability parameters, we will also include, for comparison purpose, data for cabin materials tested by P-Prime at CNRS and University of Patras, as part of the same project. Results for FTIR and ATR are not included in this paper, but a comparison of the spectra showed that the major components in the pyrolysis gases are due to the polymer resin whereas the solid residue is $95 \%$ carbon fibre material.

\subsection{Thermogravimetric Analysis}

TGA and measurements were performed using a Mettler Toledo 851 thermal analyser. 
Approximately $10 \mathrm{mg}$ of samples (filtered through a sieve with a $75 \mu \mathrm{m}$ mesh opening) were placed in an alumina crucible and then heated in the TGA apparatus from room temperature to $800{ }^{\circ} \mathrm{C}$ at constant heating rates. Tests were conducted in nitrogen with a constant flow rate of $50 \mathrm{~mL} / \mathrm{min}$. The experiments were performed at three heating rates $\left(10,15\right.$ and $\left.20^{\circ} \mathrm{C} / \mathrm{min}\right)$.

\subsection{Cone Calorimeter}

Measurements were carried out on a standard cone calorimeter provided by the Dark Star Research Ltd., UK. The cone calorimeter is the most widely used standard test (ISO 5660, 2003) for studying material flammability and toxicity. It represents the burning of a horizontal sample with a typical sample size of $100 \mathrm{~mm}$ by $100 \mathrm{~mm}$ exposed to a cone heater. The temperature of the heater can be adjusted to achieved the desired heat flux on the sample surface. Tests can be done with (piloted ignition) or without (spontaneous ignition) the ignition source (typically spark igniter). In this work, the composite samples were tested at five heat fluxes: $30,40,50,60$ and $70 \mathrm{~kW} / \mathrm{m}^{2}$. Tests were conducted in a custom-made sample holder with lower conductivity Cotronics paper on the sides and back of the sample to minimize conduction heat losses to the sample holder. A layer of aluminium sheet is placed between the sample and the insulating materials to prevent the melted polymer to soak into the insulation. As this aluminium sheet is very thin, it only absorbs a very small amount of heat. The samples were ignited using a spark igniter. For each experimental condition, three experiments have been performed to confirm the repeatability of the results. Experimental measurements consist of time to ignition, mass loss rate, heat release rate, and production of carbon monoxide and smoke, based on which the effective heat of combustion and smoke yield can also be deduced. These results together with the mass loss rate/ pyrolysis rate measured in TGA are used to deduce the flammability and toxicity parameters presented in Section 2. 


\section{Results and Discussions}

\subsection{Thermogravimetric analysis}

Figure 1 shows comparisons of weight loss (TGA) and pyrolysis rate (DTG) of the four materials at $10{ }^{\circ} \mathrm{C} / \mathrm{min}$. The results at other heating rates have similar trends. AcF2 and AcF7 have very similar onset temperatures of degradation (about $390{ }^{\circ} \mathrm{C}$ ) and maximum pyrolysis rates. For AcF1, there is a slight shift (about $20{ }^{\circ} \mathrm{C}$ higher) in both onset temperature of degradation and the temperature at which the maximum pyrolysis rate occurs. This finding would indicate that $\mathrm{AcF} 1$ is more stable than $\mathrm{AcF} 2$ or $\mathrm{AcF} 7$. In comparison, PEEK containing AcF6 has a significantly higher onset temperature of degradation and a much lower maximum pyrolysis rate that occurs at about $570{ }^{\circ} \mathrm{C}$ which is similar to the one reported by Patel et al., (2011). This result indicates that degradation of carbon fibre composites in TGA depends mainly on the thermal stability of the polymer resins.

\subsection{Time to ignition and effective ignition and flammability properties}

Table 1 summarises the time to ignition of all materials at different heat fluxes. AcF1 has the lowest times to ignition among the four materials, followed by AcF2 and AcF7 having similar times to ignition, and then by AcF6 with a significant delay in time to ignition. PEEK containing carbon fibre composite has much delayed ignition than epoxy containing composites, which is consistent with the TGA results in Fig. 1 showing that AcF6 degrades at much higher temperatures. The fact that AcF2 and AcF7 have longer ignition times than AcF1 indicates that TGA alone is not sufficient to predict the ignition of a given material, because the mg samples in TGA are heated uniformly, whereas in the cone calorimeter both conduction heat transfer and pyrolysis gases play an important role on ignition. Also shown in Table 1 is the time to ignition of the same AcF1 material but with reduced thickness $(2 \mathrm{~mm})$. Reduced times to ignition were observed at all heat fluxes for the thin samples demonstrating 
the importance of sample thickness on ignition.

By plotting the time to ignition against the external heat flux it is possible to deduce the critical heat flux/ignition temperature and effective conductivity and specific heat (Delichatsios, 2005). These properties, together with the average density calculated based on mass and volume of samples, are used in the numerical model for analysing the pyrolysis of the composites. The effective heat of combustion, $\Delta H_{c}$, determined by dividing the total heat releases by the total mass released can be used to find the stoichiometric ratio of a given material $(S)$, and subsequently the smoke point height (SPH) with the use of smoke yield, i.e., $S P H=0.084(S+1) / y_{S}$. A summary of the deduced effective ignition and thermal properties is shown in Table 2. One important observation is that AcF6 has much higher ignition temperature and critical heat flux for ignition than other materials.

\subsection{Heat release rate}

The histories of the heat release rate of all materials are shown in Fig. 2. The results show that AcF2 and AcF7 behave similarly with an initial peak followed by a short steady period and finally by a second peak due to the backside effect. AcF1 behaves almost like a thermally thin material with one single peak. In comparison, AcF6 has much lower values of HRR than epoxy containing materials, because PEEK degrades at much higher temperatures, which would imply higher surface temperature and, as a result, increased re-radiation heat losses on the surface. Note that the HRR of AcF6 at $30 \mathrm{~kW} / \mathrm{m}^{2}$ is nearly zero as it was not ignited, even though the mass loss rate data shows that there is some mass lost but the mass flux is insufficient to achieve ignition.

\subsection{Flammability and toxicity parameters}

The experimental results in TGA and the cone calorimeter (Table 1 and Figs. 1 and 2) are used to deduce the flammability and toxicity parameters by using Eqs. 1- 4. The results are 
summarized in Table 3, where it can be noted that AcF6 has the lowest values for fire growth parameter, smoke parameter and heat release rate for thermally thin conditions.

A more meaningful way for comparison is to plot the fire growth parameter against the smoke parameter (Suzanne et al., 2014) as shown in Fig. 3. As indicated in this figure, the flammability is worst at the right top corner (high values of both fire growth and smoke parameters) and best at the left bottom corner (low values of both parameters). For comparison purpose, data for cabin materials tested in the same project by P-prime at CNRS and University of Patras, are also included. The cabin materials include AcF8 (thermo-acoustic insulation), AcF9-1 (Phenolic), AcF9-6 (side bar), AcF9-7a (white layer of Ceiling Panel), AcF9-7b (black side of Ceiling Panel), AcF10 (cable), AcF11-1 (blue textile for seat), AcF11-2 (seat) and AcF12 (carpet). It can be seen that the thermoplastic resin (AcF6) composite has the best performance in terms of fire growth, whereas AcF10 (cable) produce significant amounts of heat and smoke. Figure 3 is particularly useful for comparing the flammability and toxicity of a large number of materials.

The mass residue shown in Table 3 is primarily the mass of carbon fibre which varies little from 70-75\%. The thermally thin parameter defined in Eq. 4 is plotted in Fig. 4 for three heating rates using the TGA data, where AcF6 shows the best performance. It can also be noted that this parameter is nearly independent of the heating rate.

The toxicity parameter defined in Eq. 3 provides the toxicity level of the composite relative to the polymer resin. The heats of combustion of the present materials are similar to those reported in the literature for pure epoxy or PEEK in the cone calorimeter conditions about $20 \mathrm{~kJ} / \mathrm{g}$, indicating that the composite is not more toxic than the original polymer.

\subsection{Pyrolysis Modelling for Different Formulations}

The numerical model was originally developed by the authors for a PA6 polymer 
nanocomposite (Zhang et al., 2009) and then further validated for other polymer nanocomposites (Zhang and Delichatsios, 2010) and flaxboard with intumescent coatings (Zhang et al., 2012). The fundamental parameter used to characterize the effect of the charring layer formed on top of the unpyrolysed material is a heat flux ratio defined as (Zhang et al., 2009; Zhang and Delichatsios, 2010; Zhang et al., 2012),

$$
\operatorname{ratio}_{\text {flux }}(t)=\frac{\dot{q}_{\text {net_o }}^{\prime \prime}}{\dot{q}_{n e t}^{\prime \prime}(t)}
$$

where $\dot{q}_{n e t_{-} 0}^{\prime \prime}$ is the net heat flux on the surface for the case when there is no surface layer and $\dot{q}_{n e t}^{\prime \prime}(t)$ is the actual heat flux at the interface of the char and unpyrolysed materials. The heat flux, $\dot{q}_{n e t_{-} 0}^{\prime \prime}$, can be determined based on the energy balance on the surface and is constant for a fixed external heat flux and constant ignition temperature. Prior to ignition, $\dot{q}_{n e t}^{\prime \prime}(t)$ is the same as $\dot{q}_{n e t_{-} 0}^{\prime \prime}$, i.e. the heat flux ratio is one. After ignition, $\dot{q}_{n e t}^{\prime \prime}(t)$ will decrease as the depth of char due to accumulation of carbon fibre on the surface increases. As $\dot{q}_{n e t}^{\prime \prime}(t)$ changes with time, it can only be determined numerically by solving the $1 \mathrm{~d}$ heat transfer conduction equation with the use of experimental mass loss rate. The effective ignition properties deduced from the ignition tests in Section 4.2 are used in the conduction equation. The experimental mass loss rate can also be used to estimate the pyrolysed depth, i.e., the thickness of the material that has pyrolysed, because we know the final residue of the materials based on the TGA data.

There are two assumptions in the model. The first one is one dimensional heat transfer. This is reasonable as long as the sample length/width is much larger than its thickness and there is minimal swelling and deformation of the sample during the test. For the present materials, we observed some strong non-uniform pyrolysis/burning, which would explain 
some of the differences in the predicted and measured mass loss rate shown in the next section. The other reason is that most of the CFD codes use 1D pyrolysis model and this assumption makes the implementation of the present methodology in a CFD code much easier. The second assumption is the heat losses to the sample holder are neglected because in the experiments the back of the sample was insulated with Cotronics that has very low conductivity. In applications in which heat losses are important, an additional layer should be included in the conduction equation.

The above methodology is applied to the present materials at different external heat fluxes and the deduced heat flux ratio is plotted against the pyrolysed depth in Fig. 5 and the following three cases are observed:

- For AcF1, the heat flux ratio increases linearly with the pyrolysed depth, independent of heat flux, as found for typical charring materials.

- For AcF2 and AcF7, the heat flux ratio increases almost exponentially with the pyrolysed depth independent of heat flux.

- For AcF6, the deduced heat flux ratio has significant fluctuations (note shown here) because of the complex burning behaviours of PEEK and also the oxidation of carbon fibres at high temperatures indicated by large fluctuations in the mass loss rate data. But the heat flux ratio seems to increase linearly with the pyrolysed depth at the initial stage and then remain nearly constant independent of heat flux.

The relation between the heat flux ratio and pyrolysis depth can be used to predict the mass loss rate at any heat flux and any thickness (Zhang et al., 2009; Zhang and Delichatsios, 2010; Zhang et al., 2012). This methodology is demonstrated next using AcF1 but it can also be applied to other materials. The general relation determined by the best-fit of the data as shown in Fig. 5, together with the ignition properties in Table 2, is incorporated into the 
pyrolysis model to predict the mass loss rate.

Figure 6 compares the predicted mass loss rates (MLRs) for AcF1 against the measurements at different heat fluxes. The predictions capture well the experiment trends and the predicted peak values of the mass loss rate are also in good agreement with the experimental data. A major discrepancy observed in Fig. 6 is that the experimental mass loss rate gradually decreases to zero whereas the predicted mass loss rate suddenly stops when the material becomes very thin. This difference can be attributed to the assumption in the model that heating up/pyrolysis is one dimensional, which is only approximate as the experimental observations suggested strong non-uniform pyrolysis/burning behaviours of this material. The conductive heat loss to the sample holder which is neglected in the model may also become important near the end of the experiment when the temperature becomes very high. Nonetheless, the present results show that the simple concept of the heat flux ratio can be used to explain and more importantly to predict the burning behaviours of a complex practical composite material with unknown thermal properties such as AcF1.

We further apply the methodology to predict samples with different initial thicknesses (i.e., 2, 4, 6 and $8 \mathrm{~mm}$ ), under the same heat flux of 50kW/m². The results shown in Fig. 7 demonstrate that when the sample is thin $(2 \mathrm{~mm})$ the material behaves like a thermally thin material with a much higher peak MLR. With an increase in the sample thickness, the peak MLR decreases significantly whilst the time to reaching the peak MLR increases as expected.

\subsection{Insulated back surface temperature and net heat flux}

Figure 8 compares the predicted backside temperature to the measurements at different heat fluxes. At the initial stage (prior to ignition), there is an excellent agreement between the two sets of data indicating the validity of the effective properties deduced from ignition times. As pyrolysis and combustion progress, the backside temperature continues to increase and the 
predicted temperatures become systematically higher than the measured values at all heat fluxes with a maximum difference of $80{ }^{\circ} \mathrm{C}$. A possible reason could be the use of the ignition temperature concept in the model; pyrolysis/ignition only occurs when the temperature reaches the ignition temperature and remains the same for the whole duration pyrolysis. This assumption is only approximate, as it is known that pyrolysis typically takes place in a temperature range albeit small. Another possible reason is that, as we mentioned earlier, the model does not take into account conduction heat losses to the sample holder, which could become significant towards the end of the test when the thickness of the material is small. The difference is however reduced as heat flux increases. It is also noted that in the experimental data the temperature continues to increase even after there is no more mass loss, probably due to the oxidation of carbon fibres at higher temperatures.

Figure 9 shows the measured temperature history at the insulated back surface of the sample for all materials at $50 \mathrm{~kW} / \mathrm{m}^{2}$. It is interesting to note that after about $100 \mathrm{~s}$, although the temperature varies for different materials, the temperature increase rate (the slope of temperature histories), $d T / d t$, is similar for the four materials, approximately equal to $300 / 200=1.5^{\circ} \mathrm{C} / \mathrm{s}$. Using the slope of temperature histories, the mass remaining ( $45 \mathrm{~g}$ over an area of $\left.0.01 \mathrm{~m}^{2}\right)$ and the specific heat of carbon fibres, $C=0.5 \mathrm{~kJ} /(\mathrm{kg} \cdot \mathrm{K})$, we can estimate the net heat flux into the solid as:

$$
\dot{q}_{\text {net }}^{\prime \prime}=\frac{m_{C F}}{A} C_{C F} \frac{d T}{d t} \approx \frac{45}{0.01 \times 1000} \times 0.5 \times 300 / 200=3.4 \mathrm{~kW} / \mathrm{m}^{2}
$$

This heat flux will be imposed on the insulated material behind the fuselage. We expect and have shown (for heat fluxes up to $75 \mathrm{~kW} / \mathrm{m}^{2}$ ) that same proportional reduction of the imposed heat flux (by $90 \%$ ) occurs at higher imposed heat fluxes and therefore, no flame through or flame spread will occur behind the fuselage. This method can be applied to other similar situations, such as tank fire or compartment fire, to assess the heat flux at the back of the fire 
protection material and subsequently the likelihood of flame penetration, provided that the temperature at the interface is measured and the density and specific heat of the char are known or measurable. It should however be expected that the reduction in heat flux will vary depending on the characteristics of the char and thickness of the sample.

\section{Conclusions}

We have presented two methods to evaluate and model the fire performance (flammability and toxicity) of four carbon fibre reinforced polymer composites three having epoxy resins (AcF1, AcF2 and AcF7) and one having PEEK resins (AcF6) using microscale (TGA) and mesoscale (cone calorimeter) measurements. The first method is based on a ranking method using five fire growth and toxicity parameters which are used to characterise the relative performance of these materials (Suzanne et al., 2014) and the second based on predicting using a numerical model mass the burning rate in the cone calorimeter using the effective flammability properties deduced from the ignition test ((Zhang et al., 2009; Zhang and Delichatsios, 2010; Zhang et al., 2012). The main conclusions of this work are:

1) The experimental TGA results show that for AcF6 (PEEK composite) degrades at much higher temperature than the epoxy composites (AcF1, AcF2, AcF7) owing to its high thermal stability up to approximately $550^{\circ} \mathrm{C}$ followed by $\mathrm{AcF} 1$ and then by $\mathrm{AcF} 2$ and AcF7. The final char residue is mostly due to carbon fibre.

2) The cone calorimeter results are consistent with the TGA results, with AcF6 achieving consistently better fire performance than other formulations. There are however considerable differences in the mass loss/heat release rate between $\mathrm{AcF} 1$ and other two epoxy formulations (AcF2 and AcF7) indicating the layup of carbon fibre can have a significant impact on the fire performance of material in mesoscale, in 
which heat transfer becomes important, as opposed to in the TGA test in which samples are heated almost uniformly.

3) The flammability and toxicity method confirms the experimental results (TGA and cone calorimeter), with AcF6 has the lowest fire growth parameter and toxicity parameter. This method can be used to assess the overall fire performance and toxicity of a large number of materials as demonstrated by including additional data for the cabin materials collected from the same project. The results (Fig. 3) show a wide range of these parameters due to the large differences (both chemical and physical) of these materials.

4) The numerical model previously developed for nanocomposites and intumescent coating to assess the effect of char is used for the present materials. The results confirmed our previous finding that the reduction in the heat flux due to the formation of a char layer is independent of heat flux. Three cases were observed, a linear increase of heat flux ratio with pyrolysed depth for ACF1, a nearly exponential increase of heat flux ratio with pyrolysed depth for ACF2 and AcF7 and for AcF6, the deduced heat flux ratio has significant fluctuations due to oxidation of carbon fibre at higher temperatures. The predicted mass loss rates at different heat fluxes are in reasonably good agreement with the measurements. The two main assumptions in the model (i.e., one dimensional heat transfer and the back of the sample perfectly insulated) as well as their potential impact on the results are discussed. The one dimensional heat transfer assumption is essential for this methodology to be implemented into a computational fluid dynamics (CFD) model for the prediction of fire growth in large scale applications such as in an SBI test (single burning item) as demonstrated in previous work. 
5) We have also shown based on measurement of the backside surface temperature that the heat transferred in the back of a composites is about $10 \%$ of the heat imposed on the exposed side owing primarily to the re-radiation losses from the surface (see section related to Fig. 9) and so, do not expect to have flame penetration. This method can also be applied to other similar situations in which flame penetration is important, such as tank fire or compartment fire, to assess the heat flux behind the fire protection material and subsequently the likelihood of flame penetration, provided that the temperature at the interface is measured and the density and specific heat of the char are known or measurable.

\section{Acknowledgements}

The authors acknowledge the EU for financially supporting the AircraftFire Project under Grant No 265612. The authors also thank Mr. M McKee and Mr. W Veighey for helping with the cone calorimeter experiments.

\section{References}

Branca, C., Diblasi, C.D., Galgano, A., Milella, E., 2011, Thermal and kinetic characterization of a toughened epoxy resin reinforced with carbon fibers, Thermochimica Acta 517, 5362.

Dao, D., Luche, J., Richard, F., Rogaume, T., Bourhy-Weber, C., Ruban, S., 2013. Determination of characteristic parameters for the thermal decomposition of epoxy resin/carbon fibre composites in cone calorimeter, International Journal of hydrogen energy $38,8167-8178$. 
Delichatsios, M., 1995. Critical Conditions for Upward Flame Spread and Comparison with Empirical Flammability Indices, Combust. Sci. and Techn. 106, 125-136.

Delichatsios, M.A., 2005. Piloted ignition times, critical heat fluxes and mass loss rates at reduced oxygen atmospheres, Fire Safety J. 40, 197-212.

Delichatsios, M.A., 2007. Application of upward flame spread for the prediction of SBI and ISO room corner (and parallel wall) experiments and classification, Thermal Science 11 (2), 7-22.

Delichatsios, M., Zhang, J., 2010. Micro to Mesoscale Testing and Modeling for Nanocomposite Polymers in Fires, in C. Wilkie, A. Morgan (Eds.), Fire Retardancy of Polymeric Materials, CRC.

ISO 5660-3, Reaction to Fire Tests-HEAT Release, Smoke Production and Mass Loss Rate Part 3: Guidance on Measurement, International Organization for Standardization, Switzerland, 2003.

Jubsilp, C., Panyawanitchakun, C., Rimdusit, S., 2013. Flammability and thermomechanical properties of dianhydride-modified polybenzoxazine composites reinforced with carbon fiber, Polymer Composites 34, 2067-2075

Lyon, R.E., Walters, R.A., 2002. A Microscale Combustion Calorimeter, DOT/FAA/AR-01/117, Office of Aviation Research, Washington D.C.

Nazare, S., Kandola, B., Horrocks, A.R., 2002. Use of cone calorimetry to quantify the burning hazard of apparel fabrics, Fire Mater. 26, 191-199.

Noël, D, Hechler J.J., Cole, K.C., Chouliotis, A., Overbury, K.C, 1998. Quantitative thermal characterization of carbon-epoxy composites using differential scanning calorimetry and thermogravimetric analysis, Thermochimica Acta 125,191-208. 
Patel, P., Hull, T.R., Lyon, R.E., Stoliarov, S.I., Walters, R.N., Crowley, S., Safronava, N., 2011. Investigation of the thermal decomposition and flammability of PEEK and its carbon and glass-fiber composites, Polym. Degrad. Stab. 96, 12-22.

Rallini, M., Natali, M., Kenny, J.M., Torre, L., 2013. Effect of boron carbide nanoparticles on the fire reaction and fire resistance of carbon fiber/epoxy composites, Polymer 54, $5154-5165$

Régnier, N., Fontaine, S., 2001. Determination of the thermal degradation kinetic parameters of carbon fiber reinforced epoxy using TG. Journal of Thermal Analysis and Calorimetry 64, 789-799.

Sundström, B., 2005. The Development of a European Fire Classification System for Building Products. PhD Thesis, Lund University.

Suzanne, M., Ukleja, S., Delichatsios, M.A., Zhang, J., Karlsson, B., 2014. Fundamental flame spread and toxicity evaluation of fire retarded polymers, Fire Safety Science 11, 846-859.

Tewarson, A., 2008. Smoke Emissions in Fires, Fire Safety Science 9, 1153-1164.

Toldy, A., Szolnoki, B., Marosi, G.Y., 2011. Flame retardancy of fiber-reinforced epoxy resin composites for aerospace applications. Polymer Degradation and Stability 96, 1-6.

Ukleja, S., Delichatsios, M.A., Suzanne, M., 2013. Comparison of toxicity from tube furnace with toxicity/inefficiency of combustion from Cone calorimeter for halogen free and halogenated fire retarded polymers, Proceedings of 5th International Seminar on Modern Polymeric Materials for Environmental Applications, Krakow, Poland.

Zhang, J., Delichatsios, M.A., Bourbigot, S., 2009. Experimental and numerical study of the effects of nanoparticles on pyrolysis of a polyamide 6 (PA6) nanocomposite in the cone calorimeter, Combustion and Flame 156(11), 2056-2062. 
Zhang, J., Delichatsios, M.A., 2010. Further validation of a numerical model for prediction of pyrolysis of polymer nanocomposites in the cone calorimeter, Fire Technology 46, 307-319.

Zhang, J., Delichatsios, M.A., Colobert, M., 2010. Assessment of fire dynamics Simulator for heat flux and flame heights predictions from fires in SBI tests, Fire Technology 46, 291-306.

Zhang, J., Delichatsios, M.A., McKee, M., Ukleja, S., 2012. Experimental and numerical study of burning behaviors of flaxboard with intumescent coating and nanoparticles in the cone calorimeter and single burning item tests, Fire and Materials 36 (7), 554-564. 


\section{Tables}

Table 1. Time to ignition at different heat fluxes

\begin{tabular}{l|c|c|c|c}
\hline & $30 \mathrm{~kW} / \mathrm{m}^{2}$ & $40 \mathrm{~kW} / \mathrm{m}^{2}$ & $50 \mathrm{~kW} / \mathrm{m}^{2}$ & $70 \mathrm{~kW} / \mathrm{m}^{2}$ \\
\hline AcF1 $(2 \mathrm{~mm})$ & 60.3 & 48.7 & 29.7 & 17.0 \\
\hline AcF1 $(4 \mathrm{~mm})$ & 177 & 72 & 49 & 25 \\
\hline AcF2 & 144 & 93.5 & 69 & 35 \\
\hline AcF6 & No ignition & 293 & 124.5 & 63 \\
\hline AcF7 & 141.3 & 93 & 67.5 & 33.7 \\
\hline
\end{tabular}

Table 2. Effective ignition and flammability properties deduced from the cone calorimeter

$$
\text { tests }
$$

( $\dot{q}_{c r i}^{\prime \prime}$ is critical heat flux for ignition, $T_{i g}$ ignition temperature and SPH smoke point height)

\begin{tabular}{l|c|c|c|c|c|c|c|c|c}
\hline Material & $\dot{q}_{c r i}^{\prime \prime}$ & $T_{i g}$ & $k$ & $\rho$ & $c$ & $\Delta H_{C}$ & $y_{s}$ & $y_{c o}$ & $S P H$ \\
\hline & $\mathrm{kW} / \mathrm{m}^{2}$ & ${ }^{\circ} \mathrm{C}$ & $\mathrm{W} / \mathrm{m}-\mathrm{K}$ & $\mathrm{kg} / \mathrm{m}^{3}$ & $\mathrm{~J} / \mathrm{kg}-\mathrm{K}$ & $\mathrm{kJ} / \mathrm{g}$ & $\mathrm{g} / \mathrm{g}$ & $\mathrm{g} / \mathrm{g}$ & $\mathrm{mm}$ \\
\hline AcF1 $(2 \mathrm{~mm})$ & 12 & 400 & 0.18 & 1560 & 1935 & 15 & 0.046 & 0.044 & 10.96 \\
\hline AcF1 $(4 \mathrm{~mm})$ & 13 & 420 & 0.236 & 1480 & 1993 & 19 & 0.068 & 0.043 & 9.05 \\
\hline AcF2 & 11 & 395 & 0.52 & 1550 & 1860 & 18 & 0.086 & 0.060 & 6.83 \\
\hline AcF6 & 31 & 597 & 0.38 & 1480 & 1366 & 18 & 0.047 & 0.046 & 12.59 \\
\hline AcF7 & 11 & 385 & 0.51 & 1420 & 1890 & 22 & 0.158 & 0.057 & 4.44 \\
\hline
\end{tabular}

Table 3. Fire growth parameter, smoke parameter, mass residue and thermally thin parameter

\begin{tabular}{l|c|c|c|c}
\hline \multirow{2}{*}{ Material } & $\begin{array}{c}\text { Fire Spread and } \\
\text { Growth Parameter }\end{array}$ & $\begin{array}{c}\text { Smoke } \\
\text { Parameter }\end{array}$ & $\begin{array}{c}\text { Mass } \\
\text { Residue }\end{array}$ & $\begin{array}{c}\text { Heat Release Rate for } \\
\text { thermally thin conditions }\end{array}$ \\
\cline { 2 - 5 } $\mathrm{kW} / \mathrm{m} 4-\mathrm{s}$ & $\mathrm{g} / \mathrm{kJ}$ & $\mathrm{wt} \%$ & $\mathrm{~kJ} / \mathrm{g}-\mathrm{K}$ \\
\hline AcF1 $(2 \mathrm{~mm})$ & 1605.0 & 0.00307 & - & - \\
\hline AcF1 $(4 \mathrm{~mm})$ & 836.8 & 0.00359 & 72.3 & 0.0745 \\
\hline AcF2 & 1622.1 & 0.00494 & 73.0 & 0.0677 \\
\hline AcF6 & 108.4 & 0.00261 & 74.5 & 0.0286 \\
\hline AcF7 & 1845.5 & 0.00723 & 75.3 & 0.0911 \\
\hline
\end{tabular}




\section{Figures}

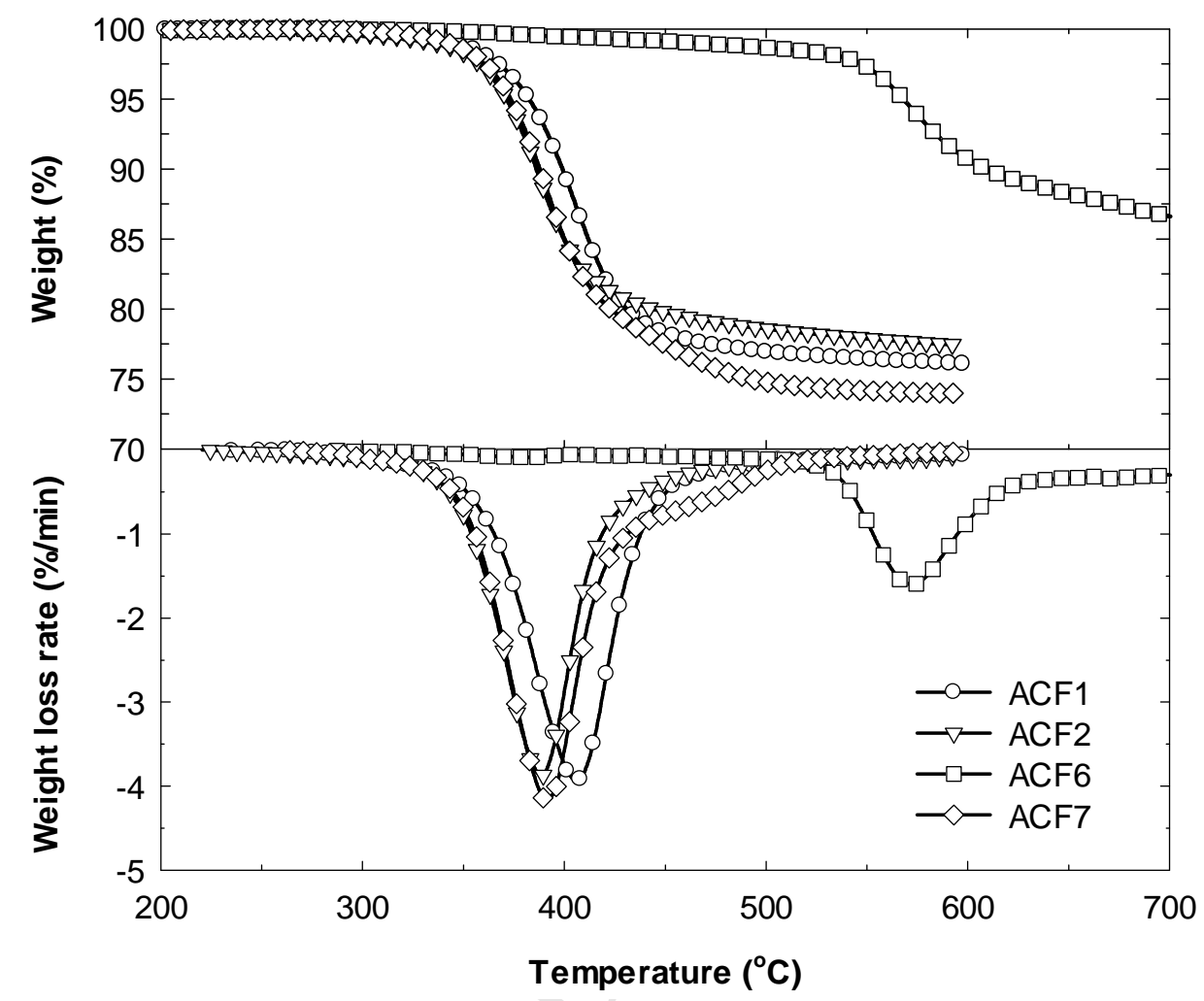

Figure 1. Comparison of weight loss (TGA) and weight loss rate (DTG) at $10{ }^{\circ} \mathrm{C} / \mathrm{min}$ in nitrogen. 


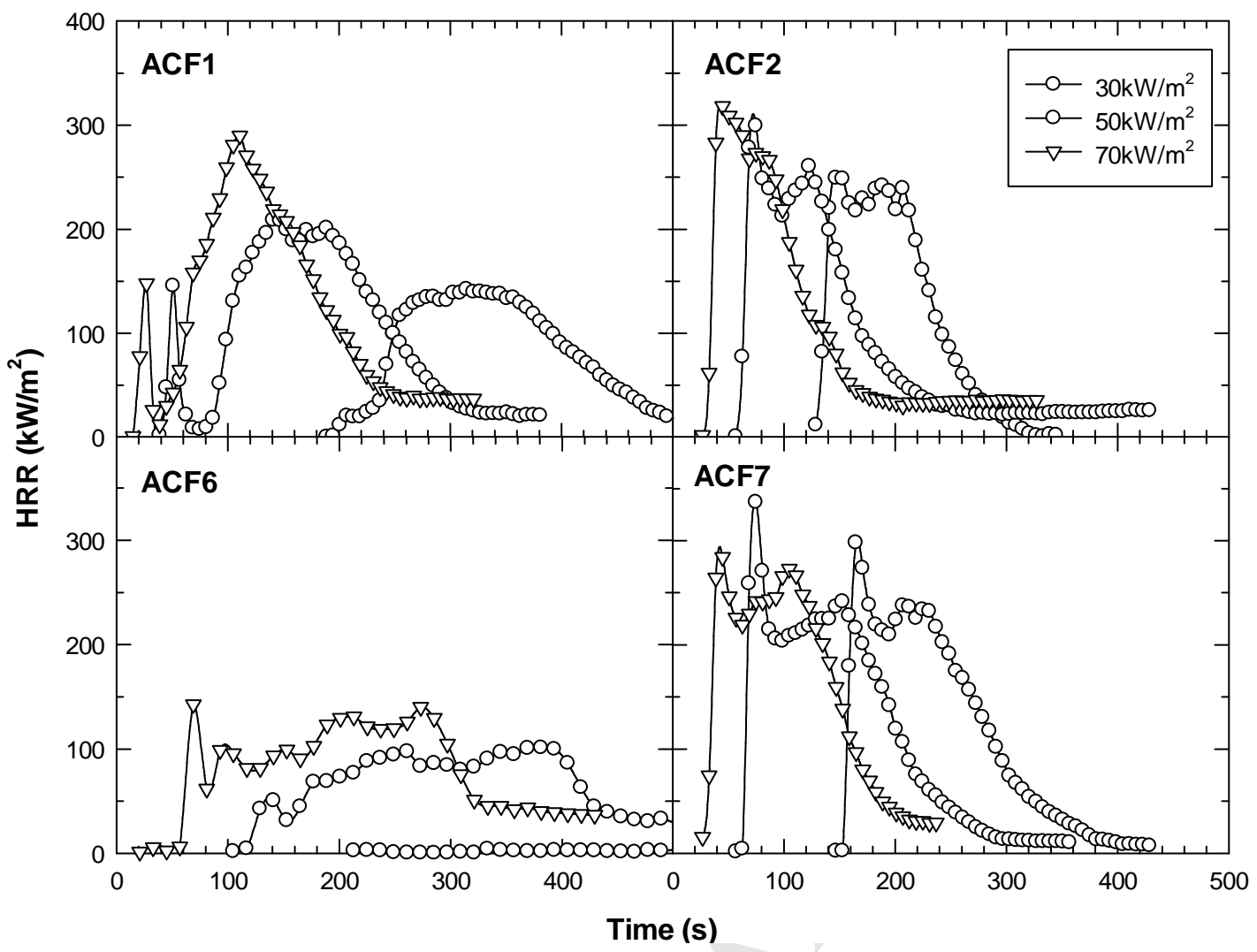

Figure 2. Comparison of heat release rate in the cone calorimeter at different heat fluxes. 


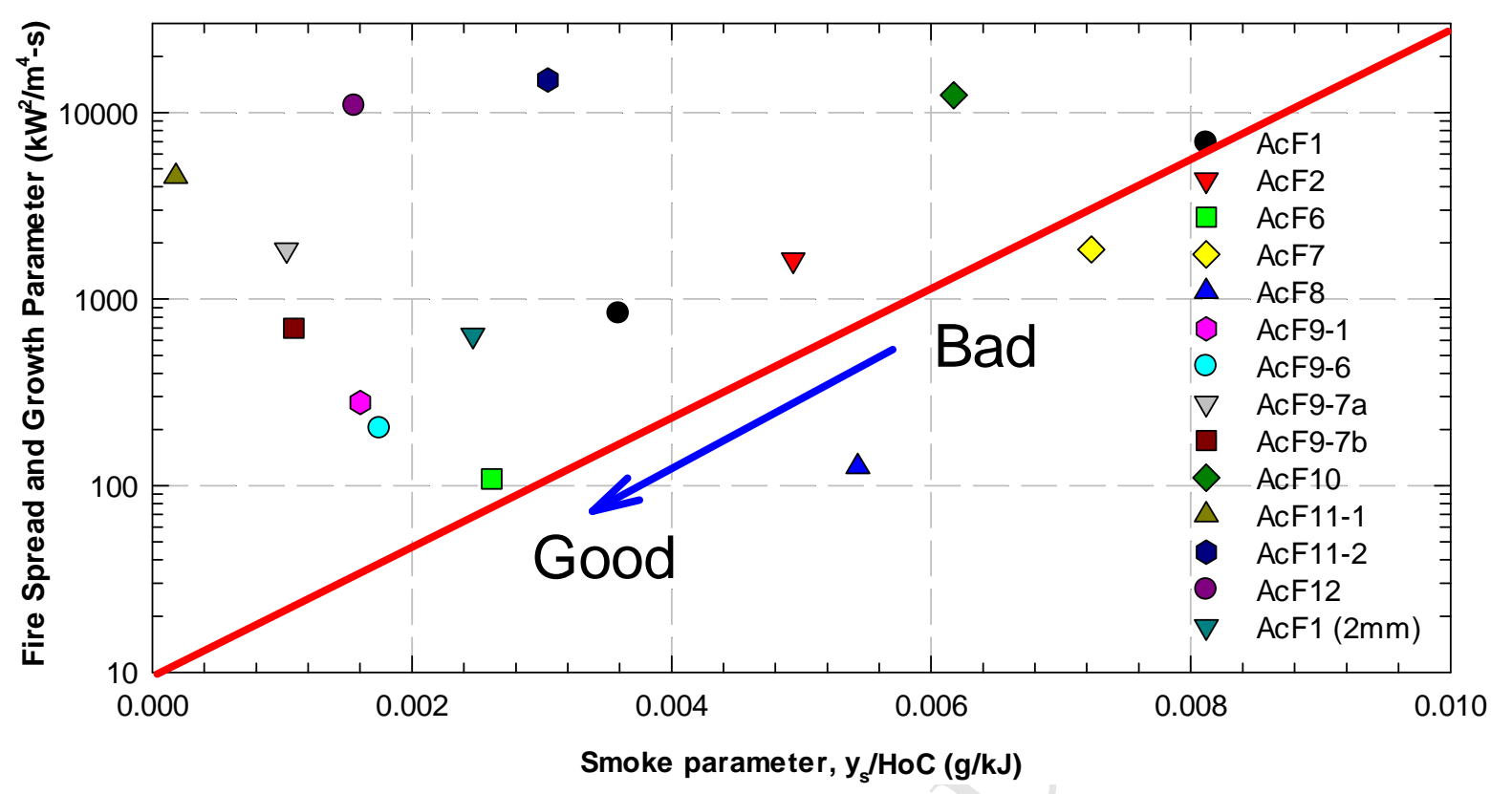

Figure 3. Fire spread and growth parameter versus smoke parameter for fuselage materials (AcF1, AcF2, AcF6 and AcF7) and cabin materials (AcF8: Thermoacoustic insulation, ACF9-1: Phenolic, AcF9-6: Sidebar, AcF9-7a: Ceiling Panel (white layer), AcF9-7b: Ceiling Panel (back side); AcF10: Cable, AcF11-1: Blue Textile, AcF11-2: Seat, AcF12: Carpet). 


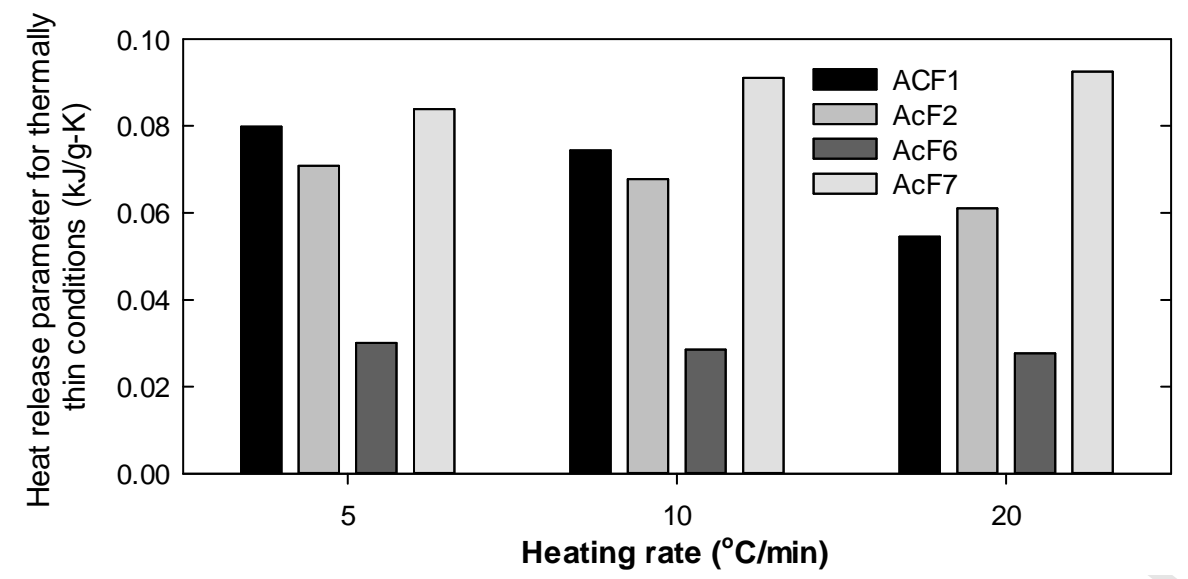

Figure 4. Heat release parameter for thermally thin conditions at three heating rates. 


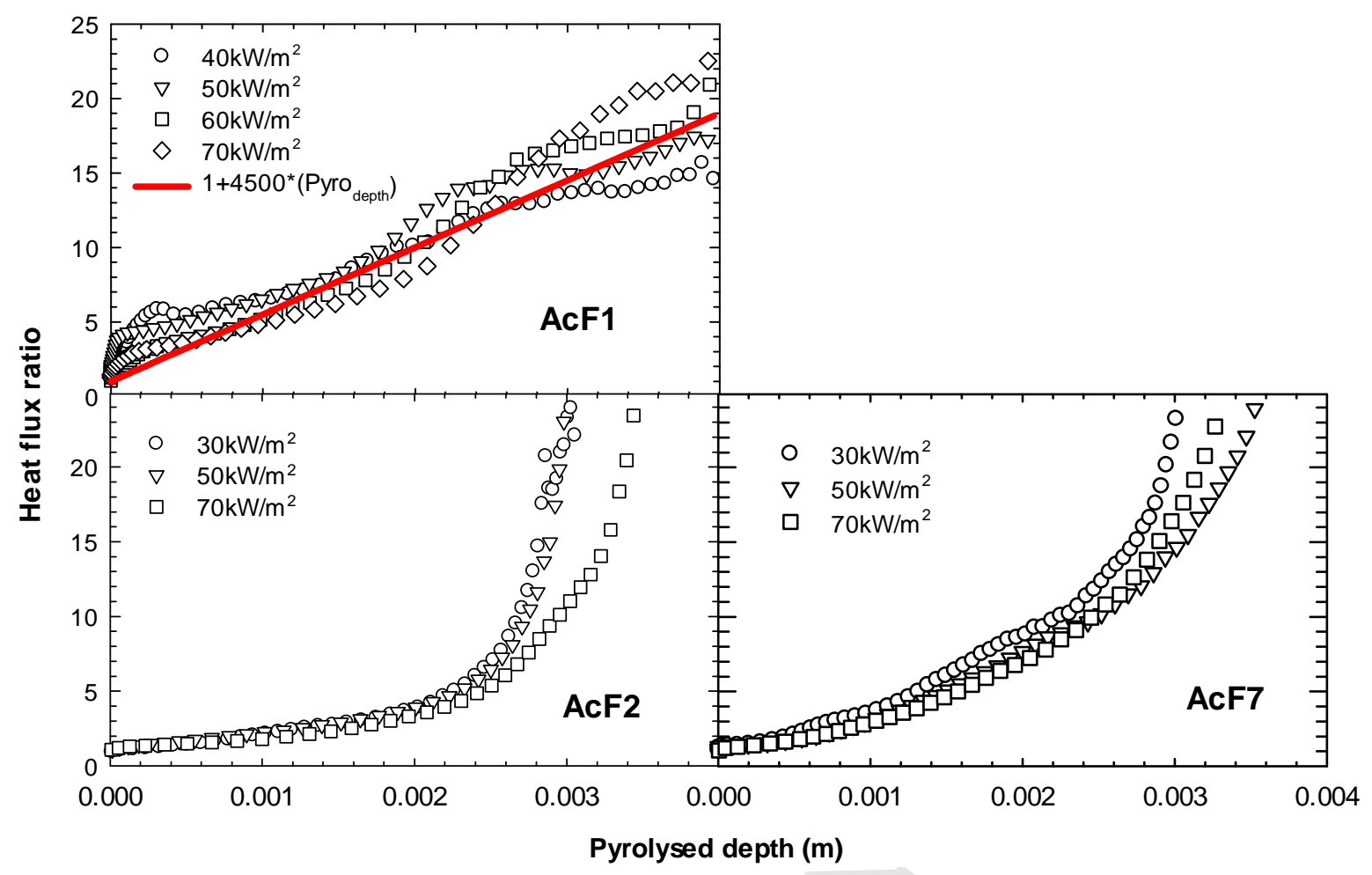

Figure 5. Calculated heat flux ratio plotted as function of the pyrolysed depth for AcF1, AcF2 and AcF7. 


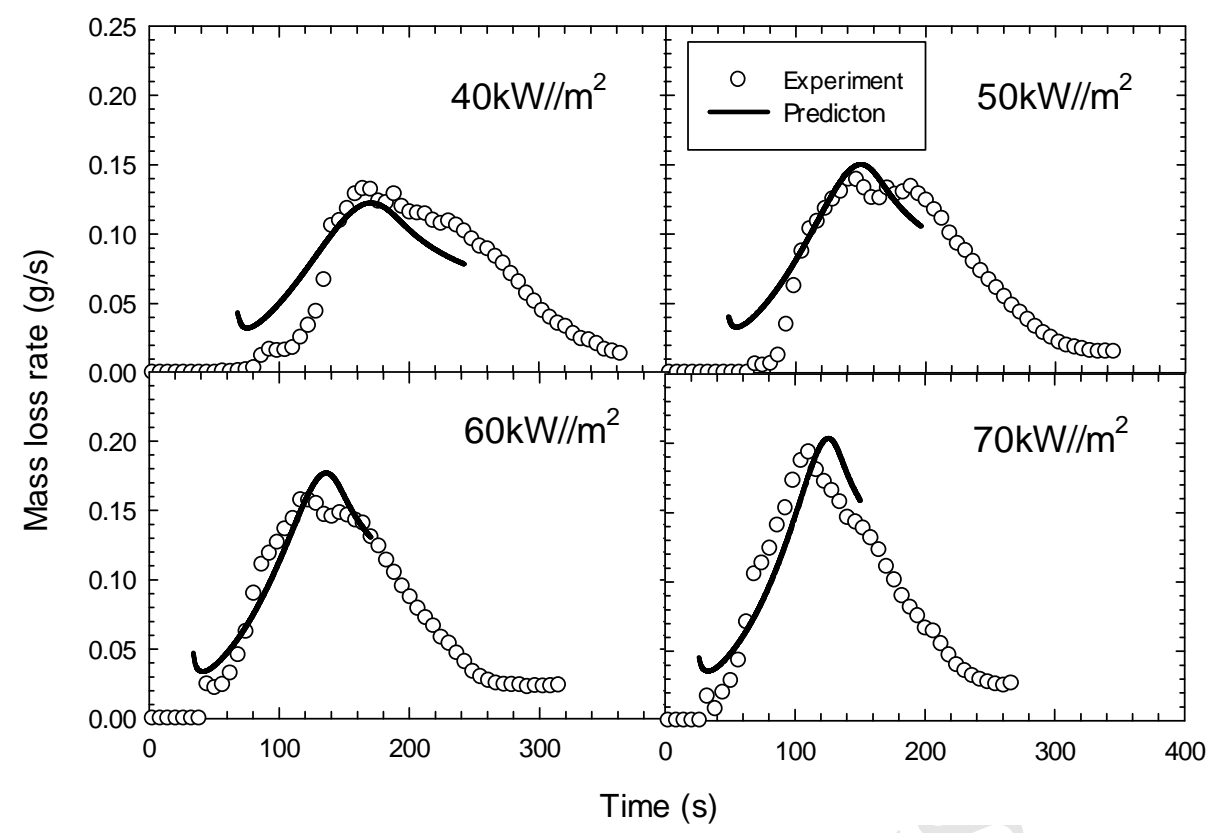

Figure 6. Comparison of predicted and experimental mass loss rate (MLR) at different heat fluxes for AcF1. 


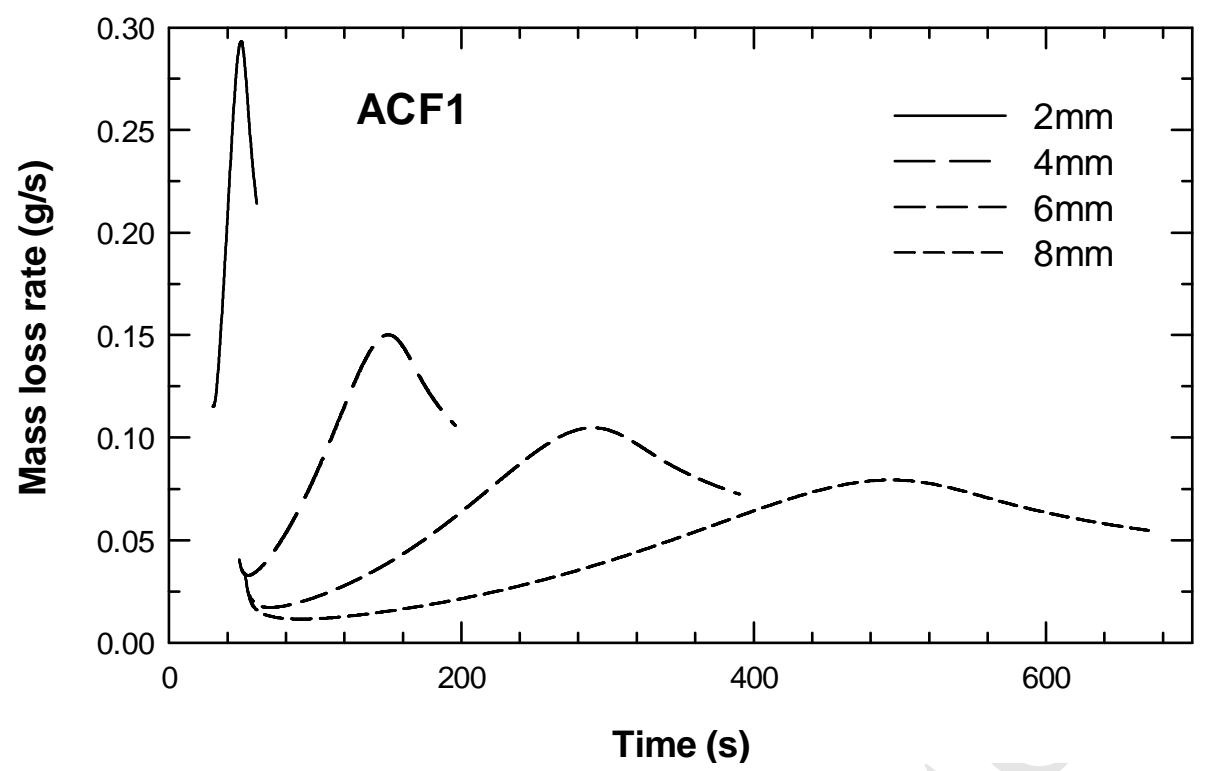

Figure 7. Predicted mass loss rate (MLR) of AcF1 with different initial samples thicknesses at $50 \mathrm{~kW} / \mathrm{m}^{2}$. 


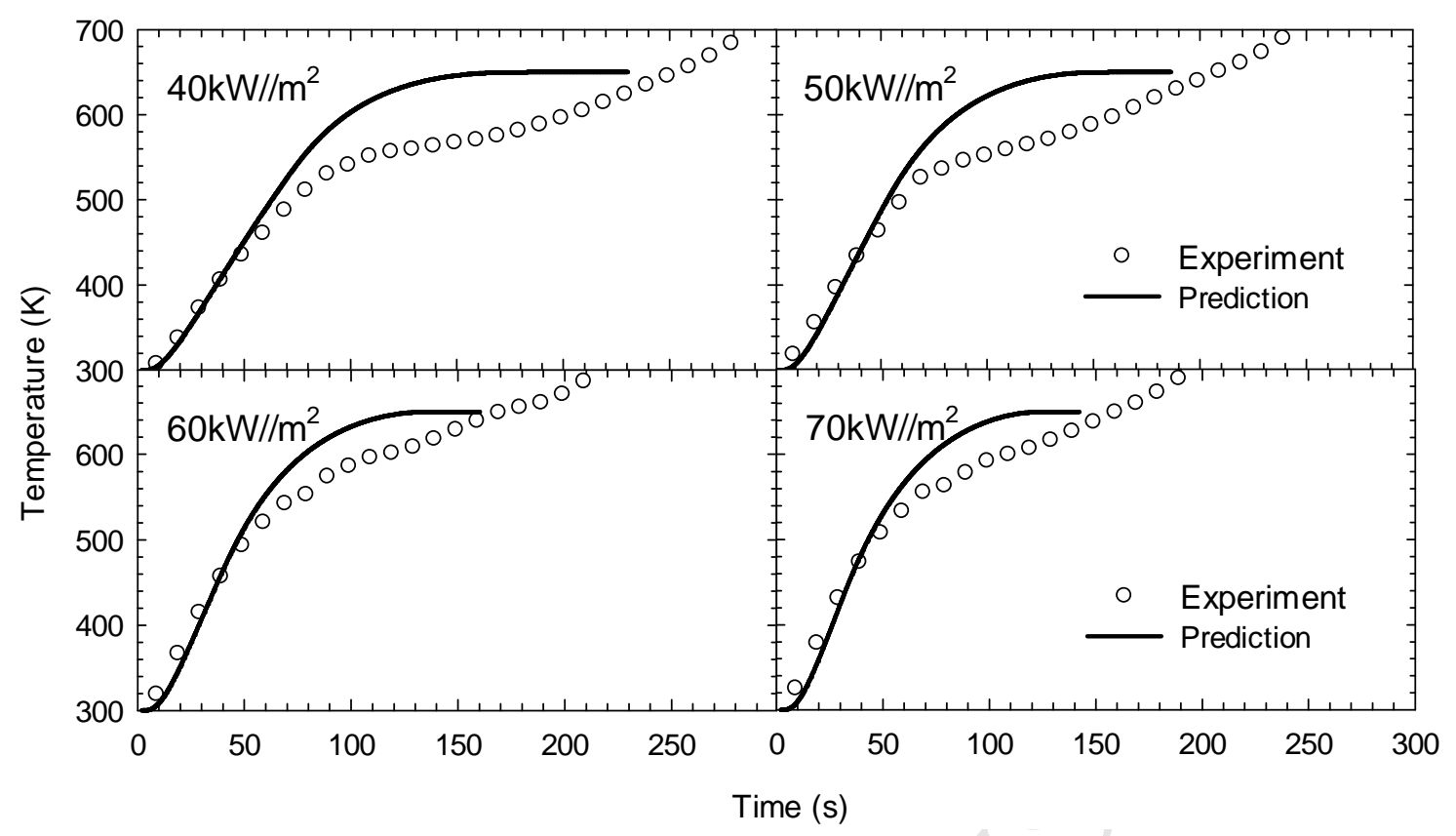

Figure 8. Comparison of predicted and experimental backside temperature at different heat fluxes for AcF1. 


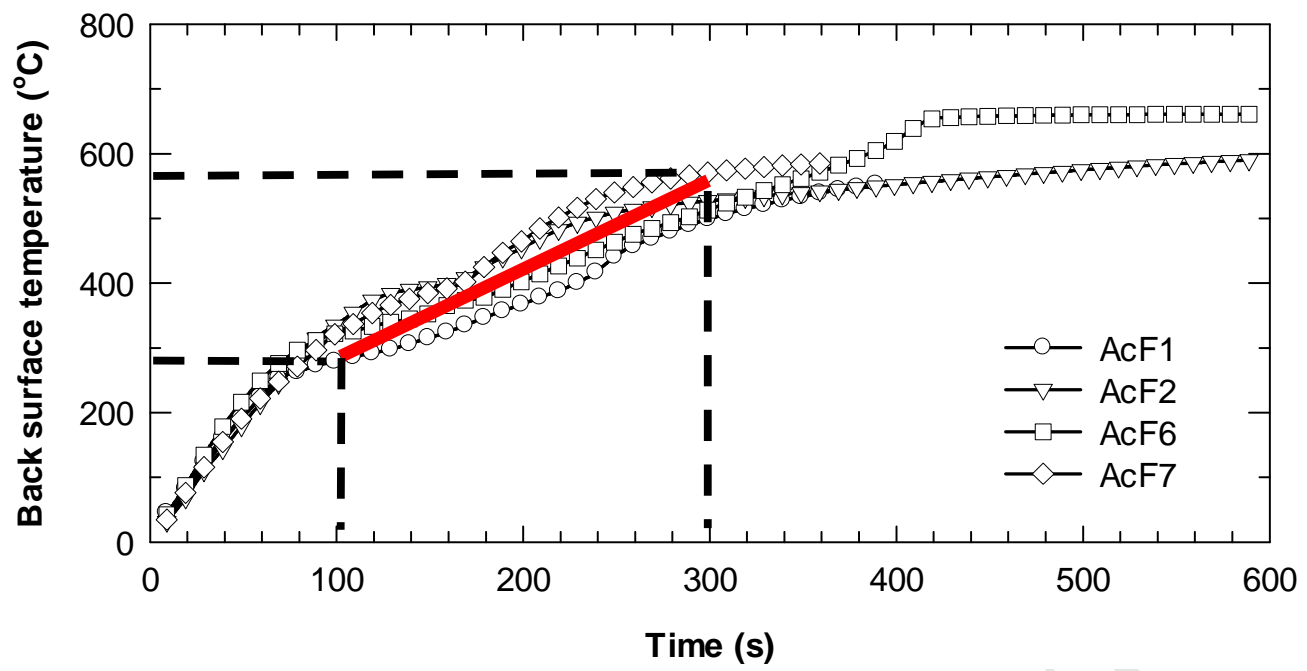

Figure 9. Comparison of the experimental backside temperature at $50 \mathrm{~kW} / \mathrm{m}^{2}$. 


\section{Figure Captions}

Figure 1. Comparison of weight loss (TGA) and weight loss rate (DTG) at $10{ }^{\circ} \mathrm{C} / \mathrm{min}$ in nitrogen.

Figure 2. Comparison of heat release rate in the cone calorimeter at different heat fluxes.

Figure 3. Fire spread and growth parameter versus smoke parameter for fuselage materials (AcF1, AcF2, AcF6 and AcF7) and cabin materials (AcF8: Thermoacoustic insulation, ACF9-1: Phenolic, AcF9-6: Sidebar, AcF9-7a: Ceiling Panel (white layer), AcF9-7b: Ceiling Panel (back side); AcF10: Cable, AcF11-1: Blue Textile, AcF11-2: Seat, AcF12: Carpet).

Figure 4. Heat release parameter for thermally thin conditions at three heating rates.

Figure 5. Calculated heat flux ratio plotted as function of the pyrolysed depth for AcF1, AcF2 and AcF7.

Figure 6. Comparison of predicted and experimental mass loss rate (MLR) at different heat fluxes for AcF1.

Figure 7. Predicted mass loss rate (MLR) of AcF1 with different initial samples thicknesses at $50 \mathrm{~kW} / \mathrm{m}^{2}$.

Figure 8. Comparison of predicted and experimental backside temperature at different heat fluxes for AcF1.

Figure 9. Comparison of the experimental backside temperature at $50 \mathrm{~kW} / \mathrm{m}^{2}$. 
- Comparative study of flammability and fire resistance of carbon fibre (CF) reinforced thermosets (epoxy resins) and thermoplastic (PEEK) using TGA and cone calorimeter

- Application of a ranking method based on flammability and toxicity parameters for carbon fibre polymer composites

- Modelling effect of carbon fibre layers using the concept of heat flux ratio developed previously for polymer nanocomposites and intumescent coatings

- Assessment of fire resistance (integrity) of carbon fibre polymer composites and heat transferred to the insulation behind this fuselage composite material based on temperature measurements in the cone calorimeter 